\title{
Optimization of Polyetherimide Based CMS Membranes Preparation Conditions for $\mathrm{CO}_{2} / \mathrm{CH}_{4}$ Selectivity
}

\author{
M. A. Ahmad ${ }^{1}$, N. K. A. Rashid ${ }^{2} \&$ B. H. Hameed ${ }^{3}$ \\ ${ }^{1,2 \& 33}$ School of Chemical Engineering, Engineering Campus, Universiti Sains Malaysia, 14300 Nibong Tebal, \\ Penang, Malaysia
}

\begin{abstract}
Response surface methodology (RSM) was used to determine the optimum preparation conditions of polyetherimide based carbon molecular sieve (CMS) membranes. Two quadratic models were developed to correlate the pyrolysis temperature, pyrolysis time and polymer concentration to the responses; $\mathrm{CO}_{2}$ permeance and $\mathrm{CO}_{2} / \mathrm{CH}_{4}$ permselectivity. According to the optimization analysis, the optimum preparation conditions were obtained by using pyrolysis temperature of $725^{\circ} \mathrm{C}$, pyrolysis time of $3.0 \mathrm{~h}$ and polymer concentration of $8.52 \%$, which resulted in $\mathrm{CO}_{2}$ permeance and $\mathrm{CO}_{2} / \mathrm{CH}_{4}$ permselectivity of $3.61 \times 10^{-10} \mathrm{~mol} / \mathrm{m}^{2}$.s.Pa and 4.35 , respectively.
\end{abstract}

Keywords: Carbon molecular sieve membranes, central composite design, gas permeation, optimization, polytherimide, pyrolysis

\subsection{INTRODUCTION}

Development of suitable membranes is the most crucial factor in determining the competitiveness of membranes technology over other separation strategies. The performance of a membrane system is measured in terms of permeability and selectivity of the target component. Suitable membrane for the gas separation process requires both high permeability and a reasonable selectivity at the same time [1]. For example, carbon dioxide $\left(\mathrm{CO}_{2}\right)$ removal from methane $\left(\mathrm{CH}_{4}\right)$ in natural gas processing using the membrane-based process was found to be an alternative to the conventional processes because of high $\mathrm{CO}_{2} / \mathrm{CH}_{4}$ selectivity, low capital cost, less space requirement, environmental friendliness and low energy consumption [2]. Therefore, many researchers have focused their interests on inorganic membrane with desirable $\mathrm{CO}_{2} / \mathrm{CH}_{4}$ separation performance, such as carbon molecular sieve (CMS) membranes.

\footnotetext{
* Corresponding to:M. A Ahmad (email; chazmier@eng.usm.my)
}

CMS membrane is one of the most promising membranes materials that have been rapidly developing in the last two decades. CMS membrane is prepared from the controlled pyrolysis of polymeric precursor. Its microstructure resembles the basic structure of the polymers but with much superior selectivity, thermal stability and strength [3]. As result, gas molecules with very similar diameter can be efficiently separate by CMS membrane under normal operation conditions. CMS membrane shows great prospect for a number of important practical separation processes, includes air separation, $\mathrm{H}_{2} / \mathrm{N}_{2}, \mathrm{CO}_{2} / \mathrm{CH}_{4}$ and olefin/paraffin [4]. Significant progress has been achieved in these areas and rooms for further improvement still largely remains. Experimental design technique by using response surface methodology (RSM) is a very useful tool as it provides statistical models which help in understanding the interactions among the variables that have been optimized for CMS membrane preparation [5]. Thus, the focus of this work was to carry out a statistical optimization to determine the optimum preparation conditions for CMS 
membrane from polyetherimide. A central composite design (CCD) was selected to study simultaneously the effects of pyrolysis temperature, pyrolysis time and polymer concentration on the $\mathrm{CO}_{2}$ permeance and $\mathrm{CO}_{2} / \mathrm{CH}_{4}$ permselectivity.

\subsection{MATERIALS AND METHODS}

\subsection{Materials}

The phenolic resin and polyetherimide were purchased from Sigma Aldrich (M) Sdn Bhd. The cellulose acetate and $\mathrm{N}$-methylpyrrolidone (NMP) were purchased from Acros Organics Ltd. The powdered fine carbon black was supplied by CarboTech GmbH. Purified $\mathrm{CO}_{2}(99.95 \%), \mathrm{CH}_{4}$ $(99.95 \%)$ and $\mathrm{N}_{2}(99.995 \%)$ were supplied by Air Product (M) Sdn Bhd.

\subsection{CMS Membrane Preparation}

The porous membrane support was made by blending phenolic resin (60\%) and carbon black $(30 \%)$ together with cellulose acetate $(10 \%)$ as binder. This blend was pressed at $1200 \mathrm{bar}$ in a static press resulting in disk-shaped supports of $20 \mathrm{~mm}$ in diamerer and $2.5 \mathrm{~mm}$ in thickness. The casting solution was prepared by dissolving polyetherimide in N-methylpyrrolidone (NMP). The mixture was stirred for $4 \mathrm{~h}$ to prepare a clear yellowish solution before coated onto the support by dip coating method and pyrolyzed under purified $\mathrm{N}_{2}$ flow $(99.99 \%)$ to form molecular sieve layer.

\subsection{Design of Experiment}

In this work, a standard RSM design, known as central composite design (CCD) was applied to study the variables for preparing the CMS membranes from polyetherimide. This method can reduce the number of experimental trials needed to evaluate multiple parameters and their interactions [6]. Generally, the CCD consists of $2^{n}$ factorial runs, $2(n)$ axial runs and six center runs, where $\mathrm{n}$ is the number of factors. The variables studied were pyrolysis temperature $(A)$, pyrolysis time $(B)$ and polymer concentration $(C)$.
Table 1 Independent variables and their coded levels for the $\mathrm{CCD}$

\begin{tabular}{|c|c|c|c|c|c|c|}
\hline \multirow[t]{2}{*}{ Variable } & \multirow[t]{2}{*}{ Symbol } & \multicolumn{5}{|c|}{ Coded variables levels } \\
\hline & & $-\alpha$ & -1 & 0 & +1 & $+\alpha$ \\
\hline Pyrolysis & & & & & & \\
\hline $\begin{array}{l}\left({ }^{\circ} \mathrm{C}\right) \\
\text { Pyrolysis }\end{array}$ & $A$ & 550 & 600 & 700 & 800 & 850 \\
\hline $\begin{array}{l}\text { time (h) } \\
\text { Polymer } \\
\text { concentration }\end{array}$ & $B$ & 0.5 & 1.0 & 2.0 & 3.0 & 3.5 \\
\hline$(\%)$ & $C$ & 5.0 & 6.0 & 8.0 & 10.0 & 11.0 \\
\hline
\end{tabular}

These three variables together with their respective ranges were chosen based on the preliminary studies as given in Table 1. For three variables, 8 factorial points, 6 axial points and 6 replicates at the center points were employed, indicating that altogether 20 experiments for this procedure, as calculated from Eq. (1):

$$
N=2^{n}+2 n+n_{c}=23+2(3)+6=20
$$

where $N$ is the total number of experiments required. The center points are used to determine the experimental error and the reproducibility of the data. The axial points are located at $( \pm \alpha, 0,0)$, $(0, \pm \alpha, 0)$ and $(0,0, \pm \alpha)$ where $\alpha$ is the distance of the axial point from center and makes the design rotatable. In this study, $\alpha$ value was fixed at 1.5. The experimental sequence was randomized in order to minimize the effect of the uncontrolled factor. The two responses were $\mathrm{CO}_{2}$ permeance $\left(Y_{1}\right)$ and $\mathrm{CO}_{2} / \mathrm{CH}_{4}$ permselectivity $\left(Y_{2}\right)$. Each response was used to develop an empirical model which correlated the response to the preparation variables using a second-degree polynomial equation as given as:

$$
\begin{aligned}
& Y=\beta_{0}+\beta_{1} A+\beta_{2} B+\beta_{3} C+\beta_{12} A B \\
& +\beta_{13} A C+\beta_{23} B C+\beta_{11} A^{2}+\beta_{22} B^{2}+\beta_{33} C^{2}
\end{aligned}
$$

where $Y$ is the predicted response. $A, B$ and $C$ are the coded forms of pyrolysis temperature, pyrolysis time and polymer concentration, respectively. The term $\beta_{0}$ is the offset term, $\beta_{1}, \beta_{2}$ and $\beta_{3}$ are the linear terms and $\beta_{11}, \beta_{22}$ and $\beta_{33}$ are the quadratic terms. 


\subsection{Model Fitting and Statistical Analysis}

The experimental data were analyzed using a statistical software Design Expert software version 6.0.6 (STAT-EASE Inc., Minneapolis, USA) for regression analysis to fit the second-degree polynomial equation and also for the evaluation of the statistical significance of the equations developed.

\subsection{Gas Permeation Studies}

Permeance of $\mathrm{CO}_{2}$ and $\mathrm{CH}_{4}$ were determined by using a gas permeation test unit with the feed pressure of $2.5 \mathrm{bar}$ and the permeate side was vacuum. The test unit was a two compartment-cell separated by the membrane and held between flanges with O-rings. Before performing the experiment, the gas permeation test unit was evacuated to less than 0.1 bar by vacuum pump for $1 \mathrm{~h}$ to remove all residual gases remaining in the cell. The rate of the permeate stream was measured using a soap bubble flow meter. Triplicate measurements were carried out for the permeation of each gas through CMS membrane in order to minimize the experimental error. The permeance was estimated using equation below [6]:

$$
P=\frac{Q}{\Delta P \times A}
$$

where $Q$ is the gas flow rate $(\mathrm{mol} / \mathrm{s}), \Delta P$ is the difference in the pressure of gases across the membrane ( $\mathrm{Pa}$ ) and $A$ is the membrane's effective surface area of membrane $\left(\mathrm{m}^{2}\right)$.

The $\mathrm{CO}_{2} / \mathrm{CH}_{4}$ permselectivity of CMS membrane was determined as the ratio of the $\mathrm{CO}_{2}$ permeance to that of $\mathrm{CH}_{4}$ permeance [8]:

$$
\propto_{\mathrm{CO}_{2} / \mathrm{CH}_{4}}=\frac{P C \mathrm{O}_{2}}{P C H_{4}}
$$

\subsection{Characterization of Optimized CMS Membrane}

The surface morphology of the sample was examined by using field emission scanning electron microscopy (FESEM, model Leo Supra $40 \mathrm{VP}$ ). The surface area, total pore volume micropore volume and pore size distribution of the sample were characterized by nitrogen adsorption at 77 $\mathrm{K}$ using Micromeritics ASAP 2020 volumetric adsorption apparatus. The surface area was determined using Brunauer-Emmett-Teller (BET) equation. Dubinin-Radushkevich (DR) equation was used to calculate the micropore volume over a range of relative pressure of $1.1 \times 10^{-5}$ to 0.02 . The total pore volume was obtained at a relative pressure of 0.99 .

\subsection{RESULTS AND DISCUSSIONS}

\subsection{Development of Regression Model Equation}

CCD was used to develop a polynomial regression equation in order to analyze the correlation between the CMS membranes preparation variables to the responses. Table 2 shows the complete design matrixes together with both the response values obtained from the experimental work. Run 15-20 at the center point were conducted to determine the experimental error and the reproducibility of the data. The $\mathrm{CO}_{2}$ permeance and $\mathrm{CO}_{2} / \mathrm{CH}_{4}$ permselectivity were found to range from $3.12 \times 10^{-10}$ to $3.58 \times 10^{-10}$ $\mathrm{mol} / \mathrm{s} . \mathrm{m}^{2}$.Pa and 2.69 to 4.77 , respectively.

According to the sequential model sum of squares, the models were selected based on the highest order polynomials where the additional terms were significant and the models were not aliased. For both responses, the quadratic models were selected as suggested by the software. The final empirical formula models for the $\mathrm{CO}_{2}$ permeance $\left(Y_{1}\right)$ and $\mathrm{CO}_{2} / \mathrm{CH}_{4}$ permselectivity $\left(Y_{2}\right)$ in terms of coded factors are represented by Eqs. (5) and (6), respectively:

$$
\begin{aligned}
Y_{1}\left(\times 10^{-6}\right)= & 3.540+0.077 A-3.560 \\
& \times 10^{-3} B+0.039 C-0.095 A^{2} \\
& -0.140 B^{2}-0.011 C^{2}-0.079 A B \\
& -6.250+10^{-4} \mathrm{AC}+0.026 B C \\
Y_{2}= & 4.120+0.410 A+0.160 B+0.073 C \\
& -0.400 A^{2}+0.110 B^{2}-0.056 C^{2} \\
& -0.200 A B-0.410 A C-0.034 B C
\end{aligned}
$$

The coefficient with one factor represent the effect of the particular factor, while the coefficients 
Table 2 Experimental design matrix

\begin{tabular}{|c|c|c|c|c|c|}
\hline \multirow[t]{2}{*}{ Run } & \multicolumn{3}{|c|}{ Factors (levels) } & \multirow{2}{*}{$\begin{array}{c}\mathrm{CO}_{2} \\
\text { permeance } \\
\times 10^{-10}, \mathrm{Y}_{1} \\
\left(\mathrm{~mol} / \mathrm{s} . \mathrm{m}^{2} . \mathrm{Pa}\right)\end{array}$} & \multirow{2}{*}{$\begin{array}{c}\mathrm{CO}_{2} / \mathrm{CH}_{4} \\
\text { permselectivity } \\
\mathrm{Y}_{2}\end{array}$} \\
\hline & $\begin{array}{c}\text { Pyrolysis } \\
\text { temperature, } \\
\mathrm{A}\left({ }^{\circ} \mathrm{C}\right)\end{array}$ & $\begin{array}{l}\text { Pyrolysis } \\
\text { time, B (h) }\end{array}$ & $\begin{array}{c}\text { Polymer } \\
\text { concentration, } \\
\mathrm{C}(\%)\end{array}$ & & \\
\hline 1 & $600(-1)$ & $1.00(-1)$ & $6(-1)$ & 3.12 & 2.88 \\
\hline 2 & $800(+1)$ & $1.00(-1)$ & $6(-1)$ & 3.45 & 4.24 \\
\hline 3 & $600(-1)$ & $3.00(+1)$ & $6(-1)$ & 3.23 & 3.55 \\
\hline 4 & $800(+1)$ & $3.00(+1)$ & $6(-1)$ & 3.23 & 4.13 \\
\hline 5 & $600(-1)$ & $1.00(-1)$ & $10(+1)$ & 3.16 & 3.14 \\
\hline 6 & $800(+1)$ & $1.00(-1)$ & $10 \cdot(+1)$ & 3.47 & 4.37 \\
\hline 7 & $600(-1)$ & $3.00(+1)$ & $10(+1)$ & 3.37 & 3.71 \\
\hline 8 & $800(+1)$ & $3.00(+1)$ & $10(+1)$ & 3.36 & 4.09 \\
\hline 9 & $550(-1.5)$ & $2.00(0)$ & $8(0)$ & 3.21 & 2.69 \\
\hline 10 & $850(+1.5)$ & $2.00(0)$ & $8(0)$ & 3.44 & 3.78 \\
\hline 11 & $700(0)$ & $0.50(-1.5)$ & $8(0)$ & 3.24 & 3.98 \\
\hline 12 & $700(0)$ & $3.50(+1.5)$ & $8(0)$ & 3.22 & 4.77 \\
\hline 13 & $700(0)$ & $2.00(0)$ & $5(-1.5)$ & 3.46 & 3.87 \\
\hline 14 & $700(0)$ & $2.00(0)$ & $11(+1.5)$ & 3.58 & 4.14 \\
\hline 15 & $700(0)$ & $2.00(0)$ & $8(0)$ & 3.54 & 4.20 \\
\hline 16 & $700(0)$ & $2.00(0)$ & $8(0)$ & 3.55 & 4.08 \\
\hline 17 & $700(0)$ & $2.00(0)$ & $8(0)$ & 3.54 & 4.11 \\
\hline 18 & $700(0)$ & $2.00(0)$ & $8(0)$ & 3.55 & 4.03 \\
\hline 19 & $700(0)$ & $2.00(0)$ & $8(0)$ & 3.55 & 4.17 \\
\hline 20 & $700(0)$ & $2.00(0)$ & $8(0)$ & 3.54 & 4.09 \\
\hline
\end{tabular}

with two factors and those with second-order terms represent the interaction between two factors and quadratic effect, respectively. The quality of the models developed was evaluated based on the correlation coefficients, $R^{2}$ value. In fact, the models developed seems to be the best at low standard deviation and high $R^{2}$ which is closer to unity as it will give predicted value closer to the actual value for the responses [7].

The $R^{2}$ values for Eqs. (5) and (6) were 0.9998 and 0.9764 , respectively. This indicated that $99.98 \%$ and $97.64 \%$ of the total variation in the $\mathrm{CO}_{2}$ permeance and $\mathrm{CO}_{2} / \mathrm{CH}_{4}$ permselectivity were attributed to the experimental variables studied. Both $R^{2}$ values were considered relatively high, indicate that the predicted values for $\mathrm{CO}_{2}$ permeance and $\mathrm{CO}_{2} / \mathrm{CH}_{4}$ permselectivity would be more accurate and closer to its actual value. In addition, the standard deviations for the two models were $3.052 \times 10^{-3}$ and 0.11 for Eqs. (5) and
(6), respectively which show the models were suitable to correlate the experimental data.

\subsection{Analysis of Variance}

The significance of the models were further justified through analysis of variance (ANOVA). The ANOVA of the regression model demonstrates that the model is significant as evident from the calculated F-value. If the value of Prob. $>\mathrm{F}$ less than 0.05 , the model terms are considered as significant [8]. The ANOVA for $\mathrm{CO}_{2}$ permeance is listed in Table 3 . The model F-value of 5327.49 and Prob. $>$ F of less than 0.0001 implied that this model was significant. In this cases, $A, B, C, A^{2}, B^{2}$, $C^{2}, A B$ and $B C$ model terms were significant whereas $A C$ was insignificant to the response. From the ANOVA for the quadratic model for $\mathrm{CO}_{2} / \mathrm{CH}_{4}$ permselectivity as shown in Table 4 , the model F-value of 45.90 and Prob, $>F$ of less than 0.0001 
Table 3 ANOVA for response surface quadratic model for $\mathrm{CO}_{2}$ permeance

\begin{tabular}{|c|c|c|c|c|c|c|}
\hline Source & $\begin{array}{l}\text { Sum of } \\
\text { squares }\end{array}$ & $\begin{array}{l}\text { Degree of } \\
\text { freedom }\end{array}$ & Mean square & F-value & Prob $>$ F & Comment \\
\hline Model & 0.450 & 9 & 0.050 & 5327.49 & $<0.0001$ & significant \\
\hline $\mathrm{A}$ & 0.073 & 1 & 0.073 & 7856.16 & $<0.0001$ & \\
\hline B & $1.584 \times 10^{-4}$ & 1 & $1.584 \times 10^{-4}$ & 17.00 & 0.0021 & \\
\hline $\mathrm{C}$ & 0.019 & 1 & 0.019 & 2032.39 & $<0.0001$ & \\
\hline $\mathrm{A}^{2}$ & 0.094 & 1 & 0.094 & 10049.50 & $<0.0001$ & \\
\hline$B^{2}$ & 0.20 & 1 & 0.200 & 21196.35 & $<0.0001$ & \\
\hline $\mathrm{C}^{2}$ & $1.319 \times 10^{-3}$ & 1 & $1.319 \times 10^{-3}$ & 141.60 & $<0.0001$ & \\
\hline $\mathrm{AB}$ & 0.050 & 1 & 0.050 & 5410.13 & $<0.0001$ & \\
\hline $\mathrm{AC}$ & $3.125 \times 10^{-6}$ & 1 & $3.125 \times 10^{-6}$ & 0.34 & 0.5753 & \\
\hline $\mathrm{BC}$ & $5.460 \times 10^{-3}$ & 1 & $5.460 \times 10^{-3}$ & 586.07 & $<0.0001$ & \\
\hline
\end{tabular}

Table 4 ANOVA for response surface quadratic model for $\mathrm{CO}_{2} / \mathrm{CH}_{4}$ permselectivity

\begin{tabular}{|c|c|c|c|c|c|c|}
\hline Source & $\begin{array}{l}\text { Sum of } \\
\text { squares }\end{array}$ & $\begin{array}{l}\text { Degree of } \\
\text { freedom }\end{array}$ & Mean square & F-value & Prob $>F$ & Comment \\
\hline Model & 4.680 & 9 & 0.520 & 45.90 & $<0.0001$ & significant \\
\hline A & 2.150 & 1 & 2.150 & 189.79 & $<0.0001$ & \\
\hline B & 0.330 & 1 & 0.330 & 29.24 & 0.0003 & \\
\hline $\mathrm{C}$ & 0.067 & 1 & 0.067 & 5.91 & 0.0354 & \\
\hline$A^{2}$ & 1.630 & 1 & 1.630 & 144.09 & $<0.0001$ & \\
\hline $\mathrm{B}^{2}$ & 0.120 & 1 & 0.120 & 10.73 & 0.0084 & \\
\hline$c^{2}$ & 0.032 & 1 & 0.032 & 2.83 & 0.1232 & \\
\hline $\mathrm{AB}$ & 0.330 & 1 & 0.330 & 29.31 & 0.0003 & \\
\hline $\mathrm{AC}$ & 0.014 & 1 & 0.014 & 1.20 & 0.2988 & \\
\hline $\mathrm{BC}$ & $9.113 \times 10^{-3}$ & 1 & $9.113 \times 10^{-3}$ & 0.80 & 0.3909 & \\
\hline
\end{tabular}

revealed that the model was also significant. In this case, $A, B, C, A^{2}, B^{2}$, and $A B$ were significant model terms whereas $C^{2}, A C$ and $B C$ were insignificant to the response. From the statistical results obtained, it was shown that the above models (Eqs. (5) and (6)) were adequate to predict the $\mathrm{CO}_{2}$ permeance and $\mathrm{CO}_{2} / \mathrm{CH}_{4}$ permselectivity within the range of variables studied.

\section{$3.3 \mathrm{CO}_{2} \quad$ Permeance and $\mathrm{CO}_{2} / \mathrm{CH}_{4}$ Permselectivity}

Based on the F-value shown in Tables 3 and 4, all the preparation variables were found to have significant effects on the responses. Pyrolysis temperature imposed the greatest effect on both responses. The pyrolysis temperature is an important parameter in shaping the pore structure of CMS membranes. As illustrated in Figures 1 and 2 , the $\mathrm{CO}_{2}$ permeance and $\mathrm{CO}_{2} / \mathrm{CH}_{4}$ permselectivity for CMS membrane were increase with increase in pyrolysis temperature in the range of $600-750^{\circ} \mathrm{C}$. At this stage, the formation of disordered structures with a very narrow porosity on the CMS membranes surface can be achieved. However at higher pyrolysis temperature, some of microporosity structure start to shrink and finally to collapse, which resulting CMS membrane with less permeable [9].

The pyrolysis time has influences on the $\mathrm{CO}_{2}$ permeance and $\mathrm{CO}_{2} / \mathrm{CH}_{4}$ permselectivity. At low pyrolysis time, the resulting membranes might not perfectly carbon membrane. The polyetherimide did not has sufficient time to break the molecular 

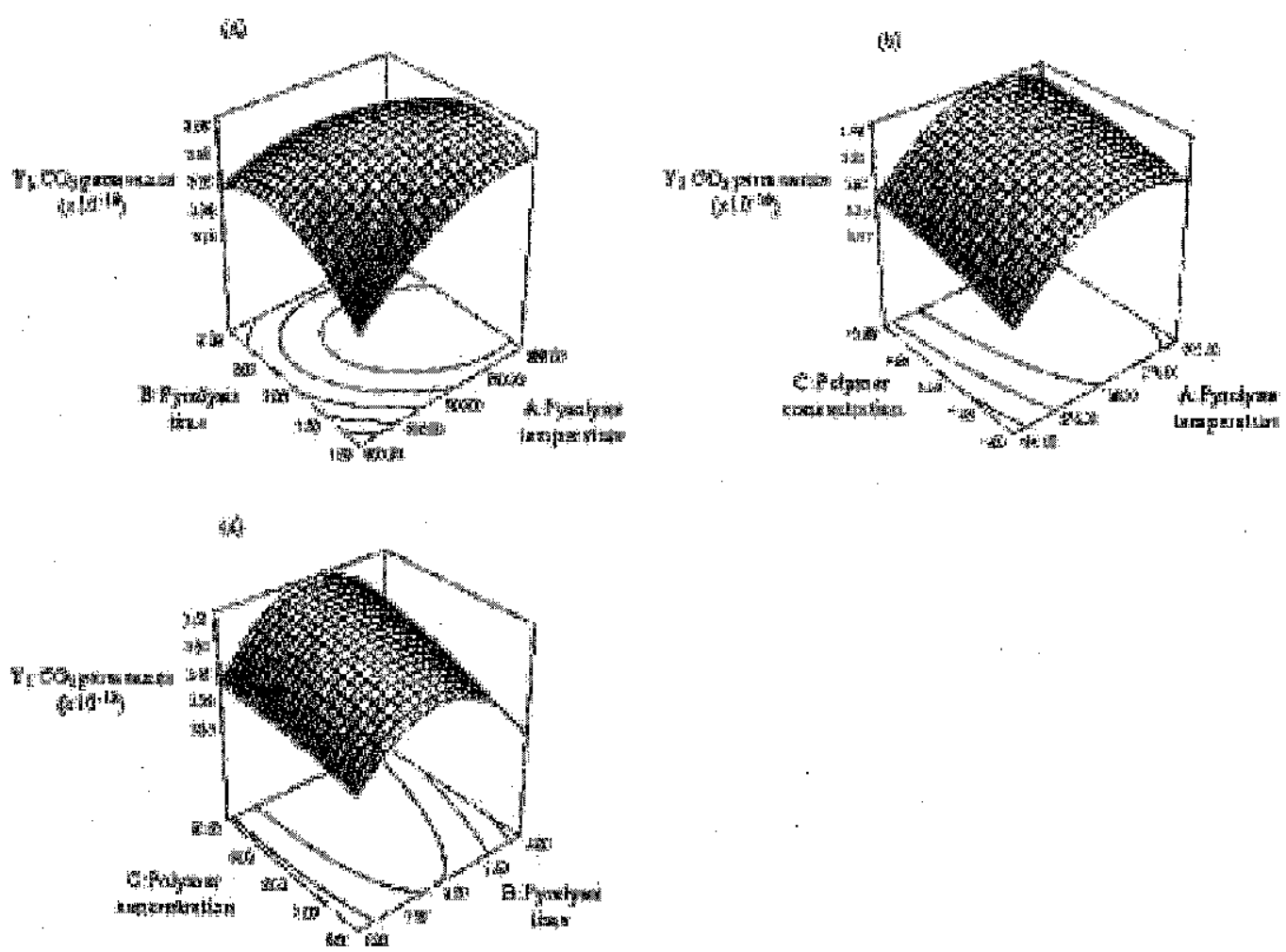

Figure 1 Three-dimensional response surface plot of $\mathrm{CO}_{2}$ permeance; (a) Effect of pyrolysis temperature and pyrolysis time, polymer concentration $=8 \%$, (b) Effect of pyrolysis temperature and polymer concentration, pyrolysis time $=2 \mathrm{~h}$ and (c) Effect of pyrolysis time and polymer concentration, pyrolysis temperature $=700^{\circ} \mathrm{C}$

chain and convert it into the carbon membranes $[10,11]$. However prolonged the pyrolysis time provides enough time for the formation of complete pore system which resulted in high $\mathrm{CO}_{2}$ permeance and $\mathrm{CO}_{2} / \mathrm{CH}_{4}$ permselectivity. As the polymer concentration increased, both responses were slightly improved.

\subsection{Process Optimization}

The aim of this study was to find the optimum preparation conditions, which CMS membrane should have a high in both $\mathrm{CO}_{2}$ permeance and $\mathrm{CO}_{2} / \mathrm{CH}_{4}$ permselectivity. The function of desirability was applied using Design-Expert software. In the optimization analysis, the target criteria was set as maximum values for the two responses while the values of the three variables were set in the ranges being studied. The experimental conditions with the highest desirability were selected to be verified. The predicted and experimental results of $\mathrm{CO}_{2}$ permeance and $\mathrm{CO}_{2} / \mathrm{CH}_{4}$ permselectivity obtained at optimum conditions are listed in Table 5 .

The optimum CMS membrane was obtained by using pyrolysis temperature, pyrolysis time and polymer concentration of $725^{\circ} \mathrm{C}, 3.0 \mathrm{~h}$ and $8.52 \%$, respectively. The optimum CMS membrane showed $\mathrm{CO}_{2}$ permeance of $3.61 \times 10^{-6}$ $\mathrm{mol} / \mathrm{s} . \mathrm{m}^{2}$.Pa and $\mathrm{CO}_{2} / \mathrm{CH}_{4}$ permselectivity of 4.35 . It was observed that the experimental values obtained were in good agreement with the values predicted from the models, with relatively small errors between the predicted and the actual values, which was only $3.05 \%$ and $1.61 \%$, for $\mathrm{CO}_{2}$ permeance and $\mathrm{CO}_{2} / \mathrm{CH}_{4}$ permselectivity, respectively. 

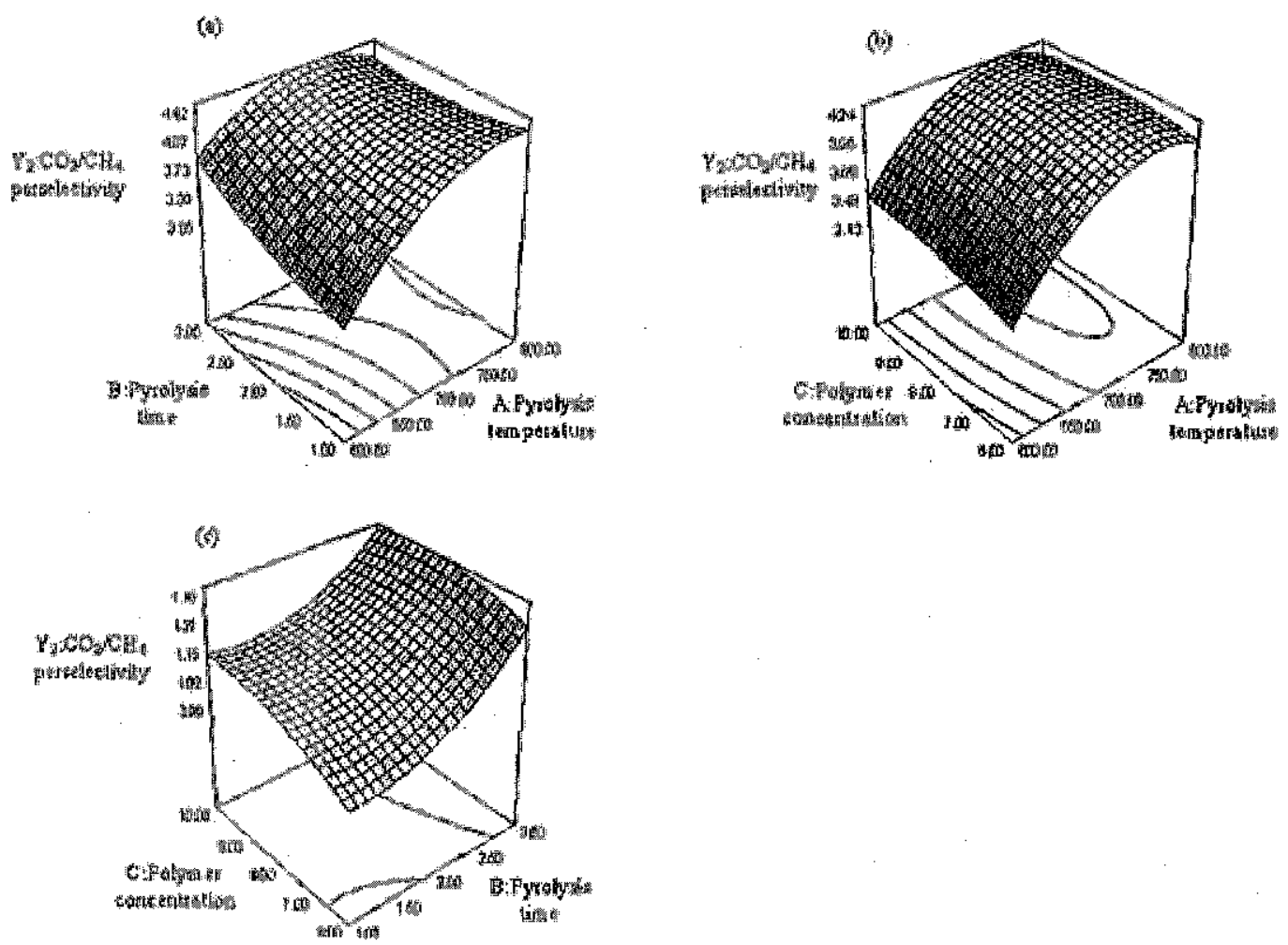

Figure 2 Three-dimensional response surface plot of $\mathrm{CO}_{2} / \mathrm{CH}_{4}$ permselectivity; (a) Effect of pyrolysis temperature and pyrolysis time, polymer concentration $=8 \%$, (b) Effect of pyrolysis temperature and polymer concentration, pyrolysis time $=2 \mathrm{~h}$ and (c) Effect of pyrolysis time and polymer concentration, pyrolysis temperature $=700^{\circ} \mathrm{C}$

Table 5 Optimal response results

\begin{tabular}{|c|c|c|c|c|c|c|c|c|}
\hline \multirow{3}{*}{$\begin{array}{c}\text { Pyrolysis } \\
\text { temperature, } \\
\mathrm{A}\left({ }^{\circ} \mathrm{C}\right)\end{array}$} & \multirow{3}{*}{$\begin{array}{l}\text { Pyrolysis } \\
\text { time, B } \\
\text { (h) }\end{array}$} & \multirow{3}{*}{$\begin{array}{c}\text { Polymer } \\
\text { concentration, } \\
\mathrm{C}(\%)\end{array}$} & \multicolumn{3}{|c|}{$\begin{array}{l}\mathrm{CO}_{2} \text { permeance } \\
\left(\mathrm{mol} / \mathrm{m}^{2} \text {.s.Pa }\right) \times 10^{-6}\end{array}$} & \multicolumn{3}{|c|}{$\begin{array}{c}\mathrm{CO}_{2} / \mathrm{CH}_{4} \\
\text { permselectivity }\end{array}$} \\
\hline & & & & & Error & & & Error \\
\hline & & & Predict & Actual & $(\%)$ & Predict & Actual & $(\%)$ \\
\hline 725 & 3.0 & 8.52 & 3.50 & 3.61 & 3.05 & 4.42 & 4.35 & 1.61 \\
\hline
\end{tabular}

\subsection{Characterization of Optimized CMS Membrane}

Figure 3 shows the morphology of the CMS membrane from top view and cross section angle. Two different parts can be distinguished, which were microporous carbon film and porous carbon support. The carbon film constitutes a dense layer with a thickness around $5 \mu \mathrm{m}$ and uniform microporous matrix form by the pyrolysis of polymeric precursor. The interface between the dense skin layer and the porous matrix is very sharp. The top layer is very smooth and almost defect-free. In addition, a good adherence between the porous matrix and the carbon support can be observed. The BET surface area, total pore volume, micropore volume and average pore diameter of the CMS membrane were $731.4 \mathrm{~m}^{2} / \mathrm{g}, 0.565 \mathrm{~cm}^{3} /$ 

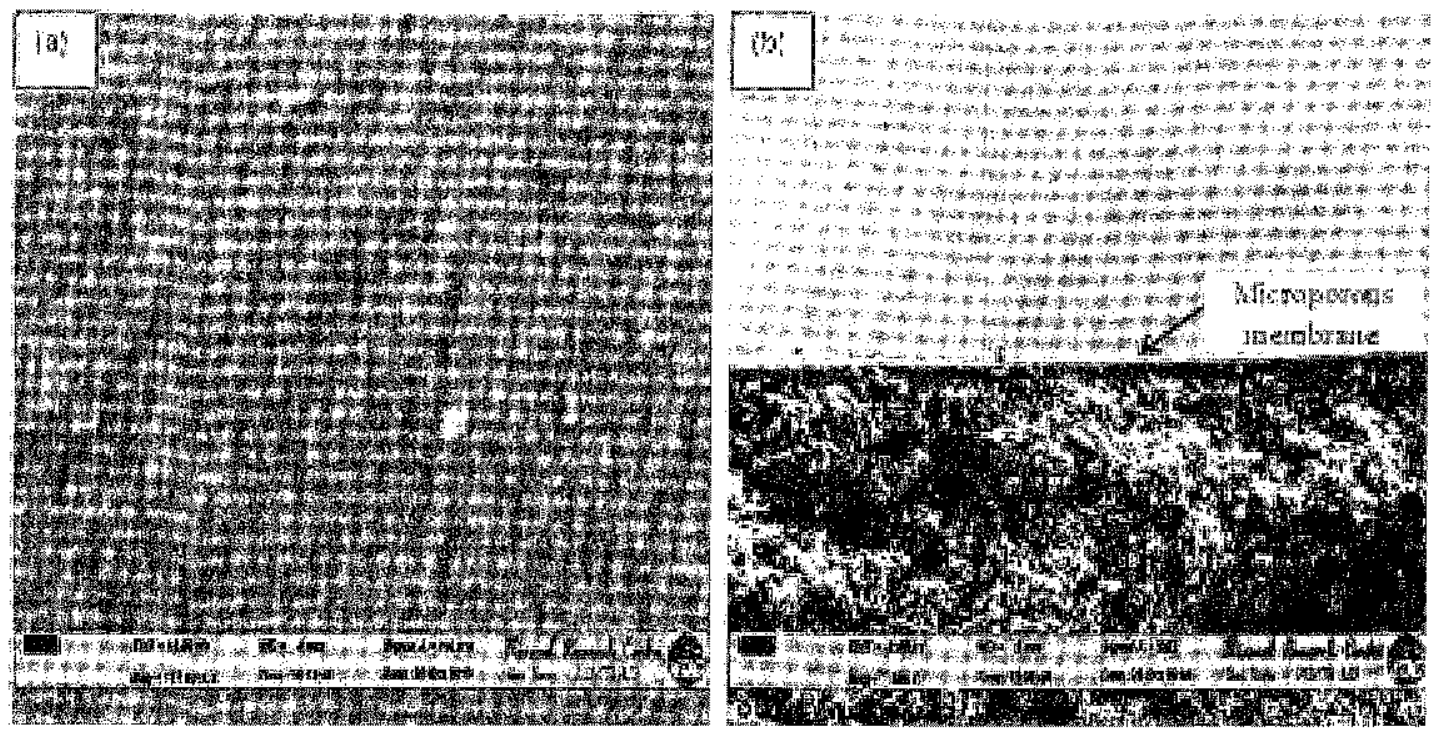

Figure 3 FESEM micrographs of CMS membrane sections: (a) top view; (b) cross-section

$\mathrm{g}, 0.481 \mathrm{~cm}^{3} / \mathrm{g}$ and $0.36 \mathrm{~nm}$, respectively. The high surface area with narrow pore size distribution indicates that the CMS membrane is suitable for gas selectivity application.

\subsection{CONCLUSIONS}

RSM was successfully used to investigate the effects of preparation variables on the $\mathrm{CO}_{2}$ permeance and $\mathrm{CO}_{2} / \mathrm{CH}_{4}$ permselectivity. The optimum preparation conditions were $725^{\circ} \mathrm{C}$ for pyrolysis temperature, $3 \mathrm{~h}$ for pyrolysis time and $8.52 \%$ for polymer concentration, resulting in $3.61 \times$ $10^{-10}$ of $\mathrm{CO}_{2}$ permeance and 4.35 of $\mathrm{CO}_{2} / \mathrm{CH}_{4}$ permselectivity. The experimental values obtained for $\mathrm{CO}_{2}$ permeance and $\mathrm{CO}_{2} / \mathrm{CH}_{4}$ permselectivity were found to agree satisfactorily with the values predicted by the models, with small error of $3.05 \%$ and $1.61 \%$, respectively. The CMS membrane demonstrates narrow pore size distribution and high surface area,

\section{ACKNOWLEDGEMENT}

The authors acknowledge the research grant provided by MOSTI (6013373) and Universiti Sains Malaysia under the Fundamental Research
Grant Scheme (6070015) that resulted in this article.

\section{REFERENCES}

[1] Iqbal, M., Z. Man, H. Mukhtar, and B. K. Dutta. 2008. Solvent Effect on Morphology and $\mathrm{CO}_{2} / \mathrm{CH}_{4}$ Separation Performance of Asymmetric Polycarbonate Membranes. J. Membr. Sci. 318: 167-175.

[2] Vu, D. Q., W. J. Koros, and S. J. Miller. 2003. Effect of Condensable Impurity in $\mathrm{CO}_{2} / \mathrm{CH}_{4}$ Gas Feeds on Performance of Mixed Matrix Membranes Using Carbon Molecular Sieves. J. Membr. Sci. 221: 233-239.

[3] Uemiya, S. 2004. Brief Review of Steam Reforming Using a Metal Membrane Reactor. Top. Catal. 29: 79-84.

[4] Wang, K., H. Suda, and K. Haraya. 2003. The Characterization of $\mathrm{CO}_{2}$ Permeation in a CMSM Derived from Polyimide. Sep. Purif. Technol. 31: 61-69.

[5] Hameed, B. H., I. A. W. Tan, and A.L. Ahmad. 2009. Preparation of Oil Palm Empty Fruit Bunch-Based Activated Carbon for Removal of 2,4,6-Trichlorophenol: Optimization Using Response Surface Methodology. $J$. Hazard. Mater. 164: 1316-1324. 
[6] Tan, I. A. W., A. L. Ahmad, and B. H. Hameed. 2008. Optimization of Preparation Conditions for Activated Carbons from Coconut Husk Using Response Surface Methodology. Chem. Eng. J. 137: 462-470.

[7] Ahmad, A. A., B. H. Hameed, and A. L. Ahmad. 2009. Removal of Disperse Dye from Aqueous Solution using Waste-Derived Activated Carbon: Optimization Study. $J$. Hazard. Mater. 170: 612-619.

[8] Sahu, J. N., J. Acharya, and B.C. Meikap. 2010. Optimization of Production Conditions for Activated Carbons from Tamarind Wood by Zinc Chloride Using Response Surface Methodology. Bioresource Technol. 10: 1974-1982.
[9] Fuertes, A. B., and T. A. Centeno. 1998. Preparation of Supported Asymmetric Carbon Molecular Sieve Membranes. J. Membr. Sci. 144: 105-111.

[10] Steel, K. M., and W. J. Koros. 2005. An Investigation of the Effects of Pyrolysis Parameters on Gas Separation Properties of Carbon Materials. Carbon. 43: 18431856.

[11] David, L. I. B., and A. F. Ismail. 2003. Influence of the Thermastabilization Process and Soak Time during Pyrolysis Process on the Polyacrylonitrile Carbon Membranes for $\mathrm{O}_{2} / \mathrm{N}_{2}$ Separation. J. Membr. Sci. 213: 285-291. 


\title{
Carbon Molecular Sieve Membranes from Polyetherimide: Effect of Pyrolysis Temperature on $\mathrm{O}_{2} / \mathrm{N}_{2}$ Selectivity
}

\author{
M. A. Ahmad ${ }^{1 *}$, N. K. A. Rashid ${ }^{2} \&$ B. H. Hameed ${ }^{3}$ \\ ${ }^{1,2 \& 3}$ School of Chemical Engineering, Engineering Campus, Universiti Sains Malaysia, 14300 Nibong Tebal, \\ Penang, Malaysia
}

\begin{abstract}
Carbon molecular sieve (CMS) membranes with excellent separation performance and stability appear to be promising candidate for gas separation. In this work, CMS membranes were formed by a thin carbon layer obtained by pyrolysis of a coated polyetherimide solution onto porous disk support. The pyrolysis temperatures were varied under inert condition. Results showed that the pyrolysis temperature played an important role in determining the gas permeability of CMS membranes. The CMS membrane prepared at pyrolysis temperature of $700^{\circ} \mathrm{C}$ shows high surface area and narrow PSD with well developed microporous carbon structures. The development of large pore occurs at higher pyrolysis temperature. The $\mathrm{O}_{2} / \mathrm{N}_{2}$ permselectivities of $2.86,2.61$ and 2.22, respectively were attained by CMS membranes prepared at pyrolyzed temperature of 700,800 and $900^{\circ} \mathrm{C}$.
\end{abstract}

Keywords: Carbon molecular sieve membranes, gas permeation, pyrolysis, polytherimide

\subsection{INTRODUCTION}

Carbon molecular sieve (CMS) membranes have received much attention for gas separation due to its superior gas permeation performance as well as high thermal and chemical stability [1]. Furthermore, CMS membranes are amorphous in nature. In addition, CMS membranes are tougher and more flexible [2]. For gas separation process, the membranes needs to exhibit molecular sieving capabilities with pore size near the dimension of gas molecules to be separated [3]. CMS membranes contain a thin carbon layer having pores with a size smaller than $1 \mathrm{~nm}$, which allow the gases separation such as oxygen $\left(\mathrm{O}_{2}\right)$ and nitrogen $\left(\mathrm{N}_{2}\right)$ from air [4]. Pure $\mathrm{O}_{2}$ is widely used for medical purposes while pure $\mathrm{N}_{2}$ is used for blanketing perishable fruits and also for shipment of flammable liquids. Suda and Haraya [5] pyrolyzed Kapton polyimide at $800^{\circ} \mathrm{C}$ and obtained CMS membrane

\footnotetext{
*Corresponding author: M. A. Ahmad (email: chazmier@ eng.usm.my)
}

with $\mathrm{O}_{2} / \mathrm{N}_{2}$ selectivity of 12 . Ghosal and Koros [6] found that the CMS membrane prepared from pyrolysizing hexafluoroisopropylidene (6-FDA)based copolyimide at $800^{\circ} \mathrm{C}$ exhibit high $\mathrm{O}_{2} / \mathrm{N}_{2}$ selectivity of 12 . In this work, polyetherimide was used for CMS membranes preparation for $\mathrm{O}_{2}$ and $\mathrm{N}_{2}$ gas permeation study. Polyetherimide has excellent physical properties and easily tunable the chemical composition by utilizing different molecular structures composed by dianhydride and diamine monomers [1].

\subsection{MATERIALS AND METHODS}

\subsection{Materials}

The phenolic resin and polyetherimide were purchased from Sigma Aldrich (M) Sdn. Bhd. The cellulose acetate and $\mathrm{N}$-methylpyrrolidone (NMP) were purchased from Acros Organics Ltd. The powdered fine carbon black was supplied by CarboTech $\mathrm{GmbH}$. Purified $\mathrm{O}_{2}$ (99.95\% purity) 
and $\mathrm{N}_{2}$ gases (99.99\% purity) were supplied by Air Product (M) Sdn Bhd.

\subsection{Membrane Preparation}

The porous membrane support was made by blending phenolic resin $(60 \%)$ and carbon black (30\%) together with cellulose acetate $(10 \%)$ as binder. This blend was pressed at 1200 bar in a static press resulting in disk-shaped support of $20 \mathrm{~mm}$ in diameter and $2.5 \mathrm{~mm}$ in thickness. Meanwhile the polymer solution which consists of $9 \mathrm{wt} \%$ polyetherimide and $91 \mathrm{wt} \%$ NMP was stirred for $4 \mathrm{~h}$ to prepare a clear yellowish solution before coated onto the support by dip coating method and pyrolyzed to form molecular sieve layer. The sample was pyrolyzed under purified $\mathrm{N}_{2}$ flow $(99.99 \%)$ to a final temperature of 700 , 800 and $900^{\circ} \mathrm{C}$ (denoted as CMS700, CMS800 and CMS900, respectively) at a rate of $2^{\circ} \mathrm{C} / \mathrm{min}$ for $3 \mathrm{~h}$.

\subsection{Permeation Measurements}

Gas permeation measurement was performed using the variable volume-constant pressure rig set up which was developed for laboratory scale. Each sample was treated prior to an elevated temperature at $100^{\circ} \mathrm{C}$ for $10 \mathrm{~min}$ to ensure that all water vapor trapped on the carbon surface was completely vaporized. The system was maintained 2.5 bar at feed section and vacuum at the permeate section. The variable volume-constant pressure method was applied for gas permeation test. Calibrated soap film flow meter was used to obtain the gas permeance penetrate traverse the membrane. The permeance was estimated using equation below [6]:

$$
P=\frac{Q}{\Delta P \times A}
$$

where $Q$ is the gas flow rate $(\mathrm{mol} / \mathrm{s}), \Delta P$ is the difference in the pressure of gases across the membrane ( $\mathrm{Pa}$ ) and $A$ is the membrane's effective surface area of membrane $\left(\mathrm{m}^{2}\right)$.

The selectivity of the membrane to specific gas is subject to the ability of the molecule to diffuse through the membrane. The permselectivity or ideal selectivity factor $\alpha$, for $\mathrm{O}_{2}$ and $\mathrm{N}_{2}$ gases is defined as:

$$
\alpha_{O_{2} / N_{2}}=\left(\frac{P_{O_{2}}}{P_{N_{2}}}\right)
$$

\subsection{Membrane Characterization}

The surface area, total pore volume micropore volume and pore size distribution of the sample were characterized by $\mathrm{N}_{2}$ adsorption at $77 \mathrm{~K}$ using Micromeritics ASAP 2020 volumetric adsorption apparatus. The surface area was determined using Brunauer-Emmett-Teller (BET) equation. DubininRadushkevich (DR) equation was used to calculate the micropore volume over a range of relative pressure of $1.1 \times 10^{-5}$ to 0.02 . The total pore volume $\left(V_{t}\right)$ was obtained at a relative pressure of 0.99. Pore size distribution (PSD) was obtained from Horvath-Kawazoe (HK) analysis. The functional group of the sample was estimated by Fourier transform infrared (FTIR) spectroscopy (FTIR-2000, Perkin Elmer). The surface morphology of the samples was examined using a scanning electron microscope (FESEM Leo Supra 40VP).

\subsection{RESULTS AND DISCUSSION}

\subsection{CMS Membranes Characterization}

Table 1 shows the properties of CMS membranes. As the pyrolysis temperature increases, the surface area and pore volume decreases. Sample CMS700 shows narrower PSD at approximately $0.41 \mathrm{~nm}$ compared to CMS800 and CMS900 as shown in Figure 1. As the pyrolysis temperature increases, the curve peak shifts to the right giving wider PSD with pore size range of $0.45-0.49 \mathrm{~nm}$. In addition, the differential pore volume $(\mathrm{d} V / \mathrm{dw})$ decreases

Table 1 CMS membranes properties

\begin{tabular}{lcccc}
\hline Sample & $\begin{array}{c}\mathrm{S}_{\mathrm{BET}} \\
\left(\mathrm{m}^{2} / \mathrm{g}\right)\end{array}$ & $\begin{array}{c}\mathrm{V}_{\mathrm{t}} \\
\left(\mathrm{cm}^{3} / \mathrm{g}\right)\end{array}$ & $\begin{array}{c}\mathrm{V}_{\text {mic }} \\
\left(\mathrm{cm}^{3} / \mathrm{g}\right)\end{array}$ & $\begin{array}{c}\mathrm{D}_{\text {mean }} \\
(\mathrm{nm})\end{array}$ \\
\hline CMS700 & 427.3 & 0.377 & 0.351 & 0.41 \\
CMS800 & 381.1 & 0.391 & 0.330 & 0.45 \\
CMS900 & 334.8 & 0.428 & 0.303 & 0.49 \\
\hline
\end{tabular}




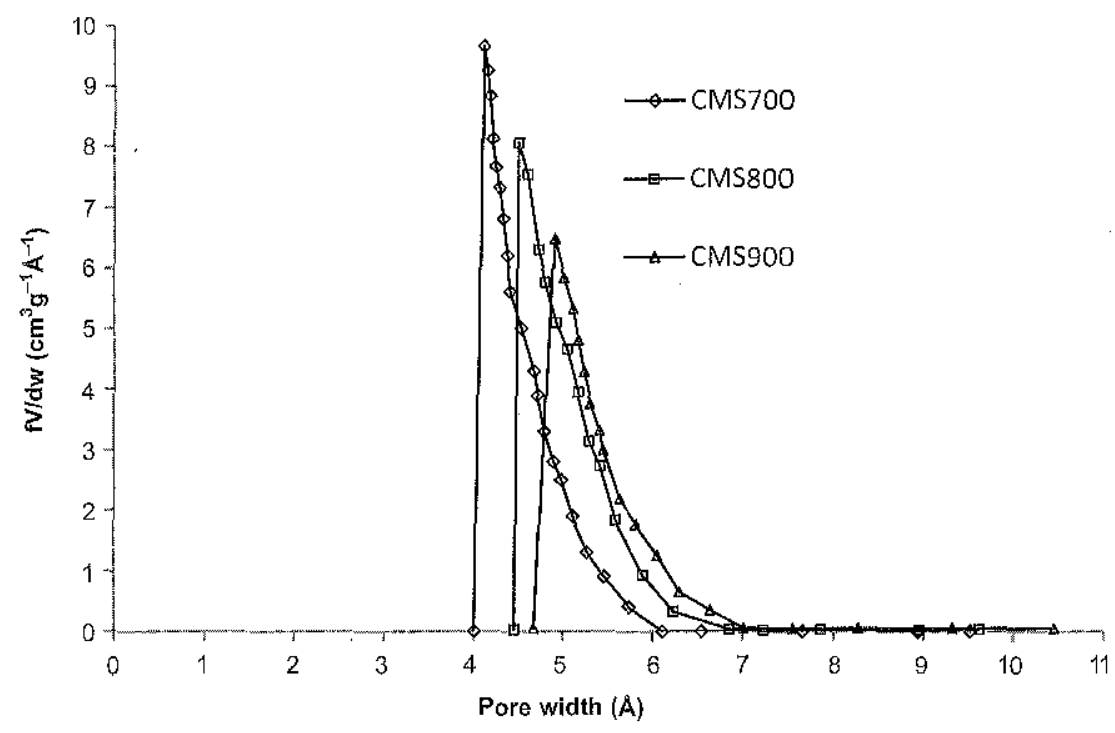

Figure 1 Pore size distribution of CMS membranes

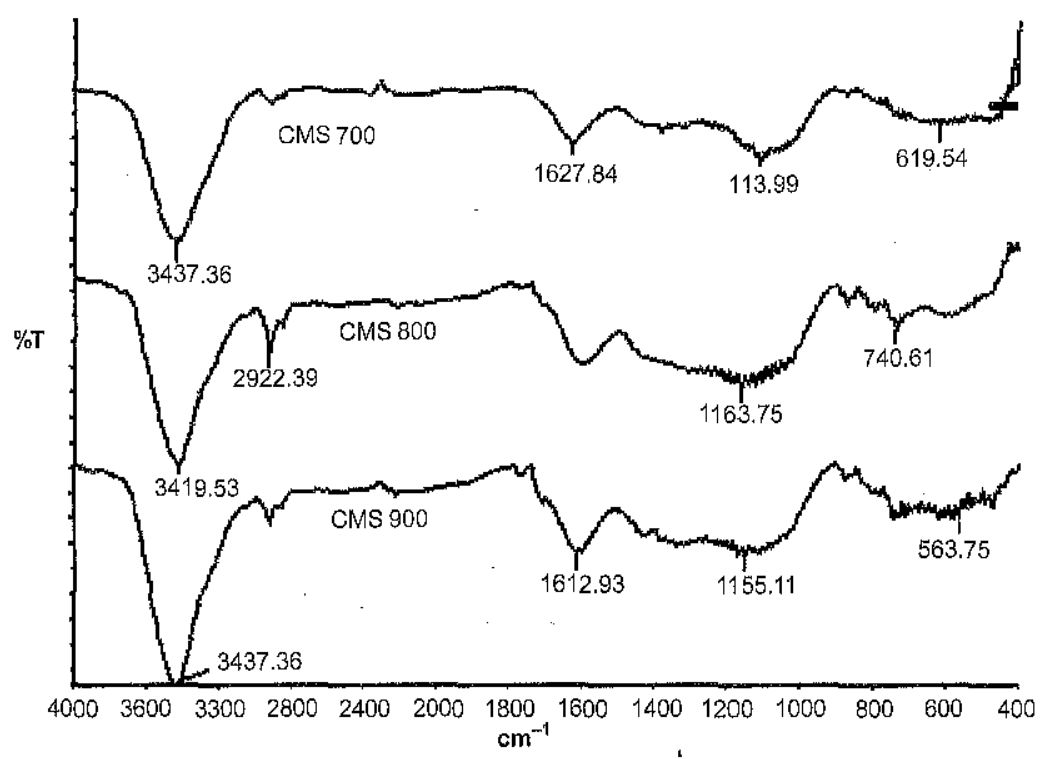

Figure 2 FT-IR spectra of CMS membranes

from 9.65 to $6.48 \mathrm{ml} / \mathrm{g} \mathrm{nm}$. At higher pyrolysis temperature, the development of the undesirable large pore begins by the burn out of walls between adjacent micropores [7].

The FTIR spectra shown in Figure 2 indicates that the peak intensities for the aliphatic or aromatic O-H $\left(3200-3500 \mathrm{~cm}^{-1}\right), \mathrm{C}-\mathrm{H}(2800-$ $\left.3200 \mathrm{~cm}^{-1}\right), \mathrm{C}=\mathrm{O}\left(\sim 1700 \mathrm{~cm}^{-1}\right), \mathrm{C}-\mathrm{N}(1100-1200$ $\left.\mathrm{cm}^{-1}\right)$ and benzene ring $\left(<750 \mathrm{~cm}^{-1}\right)$ exist in CMS membranes. The results suggest that although the PSD of the CMS membranes pyrolyzed at $700-$ $900^{\circ} \mathrm{C}$ were different but the chemical structures were almost unchanged.

Figure 3 shows the morphology of the sample CMS700 from top view and cross section angle. Two different parts can be distinguished, which were microporous carbon film and porous carbon support. The carbon film constitutes a dense 


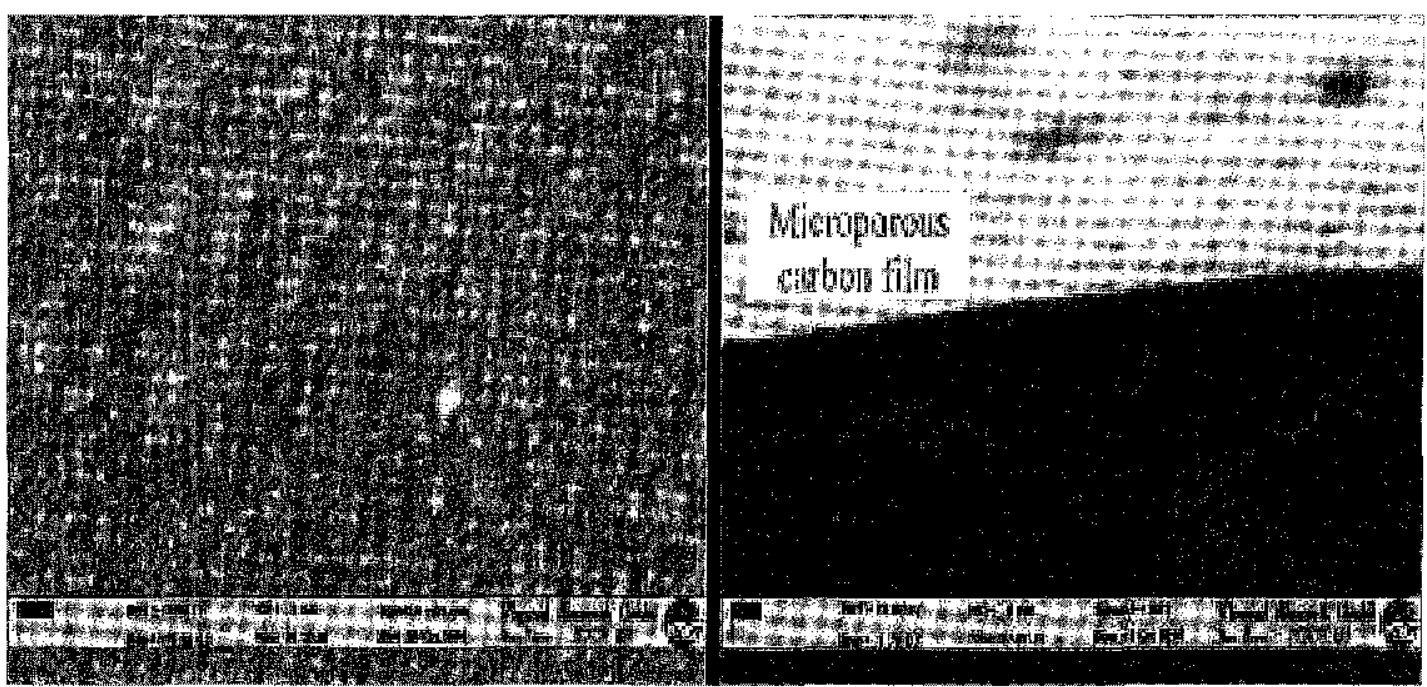

Figure 3 SEM images of CMS700; (a) top surface (117.8k $x$ ) and (b) cross sectional view (1.75k $\times$ )

layer with a thickness around $5 \mu \mathrm{m}$ and uniform microporous matrix form by the pyrolysis of polyetherimide. The top layer was very smooth and almost defect-free. The interface between the dense skin layer and the porous matrix was very sharp. A good adherence between the homogeneous porous matrix and the carbon support can be observed.

\subsection{Gas Permeation Performance}

The gas permeation result of the CMS membranes pyrolyzed at 700,800 and $900^{\circ} \mathrm{C}$ are shown in Figure 4. From the figure, the $\mathrm{O}_{2}$ has better gas

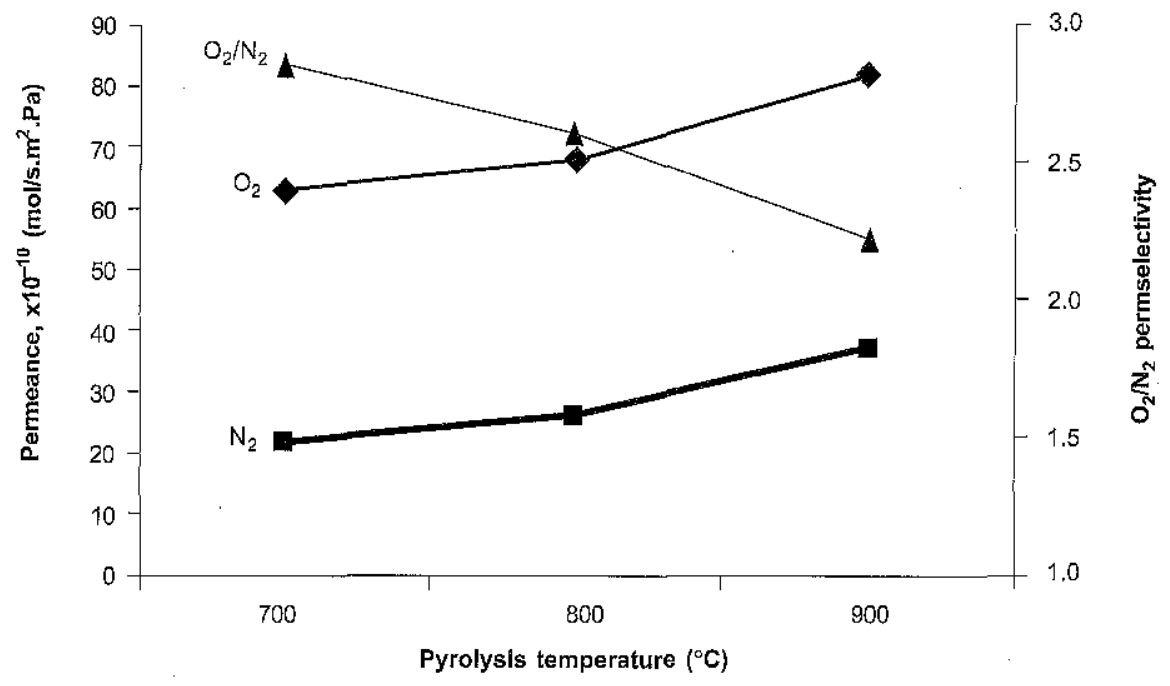

Figure 4 Gas permeance and $\mathrm{O}_{2} / \mathrm{N}_{2}$ permselectivity of CMS membranes 
permeability than $\mathrm{N}_{2}$. This was due to the comparatively higher rate of diffusion of the $\mathrm{O}_{2}$ molecule (molecular diameter $=0.346 \mathrm{~nm}$ ) into the CMS micropores than $\mathrm{N}_{2}$ molecule $(0.364 \mathrm{~nm})$ [4]. The $\mathrm{O}_{2}$ and $\mathrm{N}_{2}$ gas permeance increased with increased in pyrolysis temperature due to the formation of microporous within the carbon structure. The increase in pyrolysis temperature will also lead to a carbon membrane with higher compactness, a more turbostratic structure, higher crystallinity and density, and smaller average interplanar spacing between the graphite layers of the carbon [8]. However, as the pyrolysis temperature increased, the permselectivity decreased due to enlargement pores of the CMS membrane. Both gases can penetrate easily which result in decreased in permselectivity. The permselectivity for $\mathrm{O}_{2} / \mathrm{N}_{2}$ were $2.86,2.62$ and 2.22 for pyrolysis temperature of 700,800 and $900^{\circ} \mathrm{C}$, respectively.

\subsection{CONCLUSIONS}

At pyrolysis of $700^{\circ} \mathrm{C}$, the CMS membrane prepared shown high surface area and narrow PSD with well developed microporous carbon structures. At higher pyrolysis temperature, the surface area and pore volume decreased due to the development of large pore, which resulted in decreased in $\mathrm{O}_{2} / \mathrm{N}_{2}$ permselectivity. Sample CMS700 gave the highest $\mathrm{O}_{2} / \mathrm{N}_{2}$ permselectivity at $6.3 \times 10^{-9} \mathrm{~mol} / \mathrm{s} . \mathrm{m}^{2} . \mathrm{Pa}$ and 2.86 , respectively.

\section{ACKNOWLEDGEMENT}

The authors acknowledge the research grant provided by MOSTI (PJKIMIA/6013373) and Universiti Sains Malaysia under the Fundamental
Research Grant Scheme (PJKIMIA/6070015) that resulted in this article.

\section{REFERENCES}

[1] Youn, K. K., B. P. Ho, and M. L. Young. 2005. Preparation and Characterization of Carbon Molecular Sieve Membranes Derived from BTDA-ODA Polyimide and Their Gas Separation Properties. J. Membr. Sci. 225: 265-273.

[2] Wang, L. J., and F. C. N. Hong. 2005. Effects of Surface Treatments and Annealing on Carbon-Based Molecular Sieve Membranes for Gas Separation. Applied Surface Science. 240: 161-174.

[3] M. A. Ahmad. 2009. Preparation of Carbon Molecular Sieves from Palm Shell: Effect of Benzene Deposition Conditions. Adsorption. 15: 489-495.

[4] M. A. Ahmad, W. M. A. Wan Daud, and M. K. Aroua. 2008. Adsorption Kinetics of Various Gases in Carbon Molecular Sieves (CMS) Produced from Palm Shell. Colloids and Surfaces A: Physicochemical and Engineering Aspects. 312: 131-135.

[5] Suda, H., and K. Haraya. 1995. Molecular Sieving Effect of Carbonized Kapton Polyimide Membrane, J. Chem Soc Chem Commun. 15: 1179-1180.

[6] Ghosal, A. S., and W. J. Koros. 2000. Air Separation Properties of Flat Sheet Homogenous Pyrolytic Carbon Membranes. J. Membr. Sci. 174: 177-188.

[7] M. A. Ahmad, W. M. A. Wan Daud, and M. K. Aroua. 2007. Synthesis of Carbon Molecular Sieves from Palm Shell by Carbon Vapor Deposition. J. Porous Mater. 14: 393-399.

[8] Saufi, S.M., and A.F. Ismail. 2004. Fabrication of Carbon Membranes for Gas Separation - A Review. Carbon. 42: 241 259. 